\title{
SUBJECT MATTER IN BRIEF
}

\author{
British Journal of Nutrition 60, No. 1, July 1988
}

\section{CLINICAL AND HUMAN NUTRITION papers}

\section{STUdies IN MAN}

Fish oils and platelet plasma membrane fluidity in healthy volunteers. Consumption of fish oils rich in $n-3$ polyunsaturated fatty acids leads to accumulation of these fatty acids in cell phospholipids. In this study ingestion of $15 \mathrm{~g}$ fish oil/d by volunteers increased these fatty acids in platelets. However, gross lipid composition, function and membrane fluidity of platelets remained unaltered.

. Cellular uptake of EPA. Both resting and stimulated cultured human mononuclear cells take up exogenous eicosapentaenoic acid (EPA) rapidly. When EPA is a component of endogenous serum lipids, it is not incorporated by resting cultured mononuclear cells. Thus the practice of enriching cultured cells with fatty acids does not reflect what occurs in vivo.

Nutritional status of elderly Chinese. Anthropometric indices appropriate to elderly Chinese subjects are described. Only total body fat showed an age-related decline in women. Corrected arm-muscle area is found to be a convenient way of assessing protein status.

Effect of diet on gastric inhibitory polypeptide (GIP) and gastric emptying. Dietary fat is implicated in various diseases although its mechanisms of action are ill-defined. In man, both a low-fat diet and intravenous glucose attenuate fatstimulated GIP secretion. Intravenous glucose delays gastric emptying and modifies motilin secretion. These could be partly responsible for the altered GIP responses found.

Food ingestion after underfeeding in normal weight women. Despite marked metabolic adaptation to $7 \mathrm{~d}$ of underfeeding, there were no effects on the cardiovascular and thermogenic responses to a test meal. This study provides no evidence of any functional changes consistent with an alteration in the activity of the sympathetic nervous system due to underfeeding.

Fatty acids and the leucocyte sodium-pump. When plasma non-esterified fatty acid concentrations were raised ninefold by infusion of 'Intralipid $20 \%$ ' (trademark) with heparin, the human leucocyte total and ouabain-sensitive efflux rate constants for $\mathrm{Na}$ were significantly lowered. The leucocyte $\mathrm{Na}$ content increased, but not the potassium content. None of the calculated efflux rates changed. 


\section{Other Studies Relevant to Human Nutrition}

Dietary methionine and selenomethionine. Selenium increased in erythrocytes and muscle but glutathione peroxidase activity decreased in plasma, liver and muscle in methionine-deficient rats compared with methionine-supplemented rats when given $0.5 \mathrm{mgSe}$ as selenomethionine $/ \mathrm{kg}$. These results suggest that selenomethionine may not be the optimum form to use for Se supplementation.

Malnutrition and nutritional rehabilitation. The effects of the period of shortterm nutritional rehabilitation of rats after pre- and postweaning protein-energy malnutrition on growth, and insulin and glucagon were studied. Except after long-term malnutrition, rehabilitation always produced a similar beneficial effect on catch-up growth. High insulin sensitivity may facilitate this effect.

\section{GENERAL NUTRITION papers}

Protein synthesis in lambs. Rates of protein synthesis were measured in some major tissues and whole body of sucking lambs by a large injection of $\left[{ }^{3} \mathrm{H}\right]$ valine. Protein fractional synthesis rates and the partitioning of protein synthesis between tissues were similar to those recently reported in immature rats, piglets and chicks by flooding-dose experiments.

Effects of cimaterol on rats. Cimaterol, a $\beta$-agonist, increases lean gain at the expense of fat in meat animals. Effects of cimaterol on protein and fat gains in various organs and tissues were examined. Growing rats fed on cimaterol gained more carcass and muscle protein than controls, and actually lost subcutaneous and whole-body fat.

Absorption of amino nitrogen and glucose in pigs. After ingestion of a semisynthetic diet containing fish-meal proteins, the amount of nitrogen and glucose appearing in the portal vein increased with increasing level of protein and carbohydrate ingestion while the percentage absorption decreased, that of glucose being lower than that of amino-N.

Absorption of fish meal amino acids in pigs. In unanaesthetized pigs given semisynthetic diets containing fish-meal proteins, aromatic amino acids (AA) showed the highest hourly absorption coefficients $(0 \cdot 10 / \mathrm{h})$, and sulphur-AA, lysine and arginine the lowest ones $(0.056-0.07 / \mathrm{h})$. Alanine, citrulline and ornithine were synthetized in the gut wall.

Duodenal perfusions of nitrogen products. Infusions into the pig duodenum of a milk-protein enzymic hydrolysate and free amino acids (AA) with the same AA pattern were compared. AA, other than methionine, entered the portal vein more rapidly and in greater amounts and glucagon production was greater after infusion of the hydrolysate.

Digestion of grazed forages. Portable infusion and sampling apparatus with cattle grazing contrasting ryegrass and white clover swards were used to estimate 
duodenal nutrient supply and ruminal digestion. Differences between forage species and their stage of maturity are discussed and related to a previous study where similar forages were offered to housed cattle.

Food restriction and growth efficiency in rats. The purpose of the study was to evaluate the relation between incremental levels of food intake and the resulting equilibrium body-weight. The present findings indicate that maintenance requirements are directly proportional to body-weight, and growth efficiency is related to food consumption rates.

Leucine metabolism in the rumen of sheep. Infusion of $\left[{ }^{3} \mathrm{H}\right]$ leucine into the rumen resulted in the leucine in the microbial protein being heavily labelled. Approximately $50 \%$ of microbial leucine originated from the rumen free pool. Intravenous infusion of $\left[{ }^{3} \mathrm{H}\right]$ leucine also labelled the rumen micro-organisms. Evidence suggested that this labelling resulted from bacteria adhering to the rumen epithelium.

Quality improvement of ensiled sweet potato. A diet containing raw sweetpotato (Ipomoea batatas L. Lam.) roots (SPR) caused growth retardation and pancreatic enlargement in rats but diets with ensiled SPR did not. The improvement was not due to changes of general composition, amino acids and fatty acids; it was associated with a decrease in trypsin-inhibitor activity.

Hemicellulose and pectin degradation. Forage carbohydrate polymers are the main source of energy for herbivores. Caecal micro-organisms in the horse break down plant structural polysaccharides (cellulose, hemicellulose, pectin). The enzymes involved (polysaccharide depolymerases and glycosidases) appear to be most important in the caecal fractions that contain protozoa. 